\title{
Avaliação do aluno surdo na escola regular: pressupostos legais e experiências
}

\author{
Evaluation of the deaf student in the regular school: legal assumptions and experiences \\ Évaluation des élèves sourds à l'école ordinaire: hypotheses et experiences légaux
}

Adriana Moreira de Souza Corrêa ${ }^{1}$ Universidade Federal de Campina Grande

\author{
Aparecida Carneiro Pires ${ }^{2}$ \\ Universidade Federal de Campina Grande
}

Francileide Batista de Almeida Vieira ${ }^{3}$

Universidade Federal do Rio Grande do Norte

\begin{abstract}
Resumo: O presente trabalho objetivou identificar (na legislação e na literatura) pressupostos, recursos e práticas de avaliação para surdos. Para tal, definimos como percurso metodológico a pesquisa exploratória, pautada na análise documental e na revisão da literatura, embasando-se em Brasília (2014), Brasil (1996, 2015), Libâneo (2007), Luckesi (2011), Hoffmann (2011; 2013) entre outros. Apresentamos uma análise bibliográfica, baseada na legislação que trata da avaliação voltada para o aluno surdo e em resultados de 7 pesquisas. Identificamos que é necessária a formação continuada para modificar a atuação docente ante a avaliação, compreendendo a colaboração de outros profissionais e membros da comunidade escolar no processo avaliativo.
\end{abstract}

Palavras-chave: Avaliação. Políticas de Educação Inclusiva. Surdo.

Abstract: The evaluation of learning aims to provide an understanding of the consolidated knowledge and rethinking the educational practices in order to favor the learning of the students. Based on these considerations, this study aimed to identify (in legislation and literature) assumptions, resources and evaluation practices for the deaf in order to reflect on the conditions that optimizes this process. Therefore, we defined as as methodological path the exploratory research, based on the documental analysis and the literature review, whose foundation was based on Brasilia (2014), Brasil (1996, 2015), Libâneo (2007), Luckesi (2011), Hoffmann (2011, 2013), among others. Thus, we present a qualitative bibliographical analysis, based on the legislation that deals with the evaluation focused on the deaf student and on the results of 7 researches that discusses resources and strategies to favor the optimization of this process. We identified the need for continuous training to modify the teaching performance on the evaluation, with other professionals and members of the school community in the evaluation process.

\footnotetext{
${ }^{1}$ Especialista em Educação Especial. Professora de Libras da Universidade Federal de Campina Grande/Centro de Formação de Professores. E-mail: adriana.korrea@gmail.com. ORCID: https://orcid.org/0000-0002-20604739. Lattes: https://orcid.org/0000-0002-2060-4739.

${ }^{2}$ Doutora em Educação. Professora Adjunto II do Curso de Pedagogia, da Universidade Federal de Campina Grande/Centro de Formação de Professores. E-mail: cidaufcg2017@gmail.com. ORCID: https://orcid.org/o000-0001-6219-585X. Lattes: http://lattes.cnpq.br/5613969088897311.

${ }_{3}$ Doutora em Educação. Professora Adjunta da Universidade Federal do Rio Grande do Norte. E-mail: leidaalmeida@gmail.com. ORCID: https://orcid.org/0000-0002-7980-1155. Oattes: 
Keywords: Evaluation. Inclusive Education Policies. Deaf.

Résumé: Le présent travail visait à identifier (dans la législation et la littérature) des hypothèses, des ressources et des pratiques d'évaluation pour les sourds. À cette fin, nous définissons la recherche exploratoire comme la voie méthodologique, basée sur l'analyse documentaire et la revue de littérature, basée sur Brasilia (2014), le Brésil (1996, 2015), Libiliar (2007), Luckesi (2011) et Hoffmann (2011). ; 2013) parmi d'autres. Nous présentons une analyse bibliographique, basée sur la législation qui traite de l'évaluation destinée à l'étudiant sourd et sur les résultats de 7 recherches. Nous avons constaté qu'une formation continue était nécessaire pour modifier le rendement de l'enseignement avant l'évaluation, y compris la collaboration d'autres professionnels et de membres de la communauté scolaire dans le processos d'évaluation.

Mots-clés: Évaluation. Politique d'éducation inclusive. Sourds

\section{Introdução}

A avaliação, enquanto elemento integrante do processo de ensino e de aprendizagem, precisa passar por constantes reflexões que se referem à sua conceituação e implementação, tendo como foco o favorecimento para que os objetivos sejam alcançados. Neste sentido, deve implicar na investigação sobre alternativas que venham a interferir tanto nas estratégias de aplicação quanto nos instrumentos de coleta de dados e de análise do desenvolvimento do educando.

Neste contexto de flexibilização do conceito de avaliação, observamos outra nuance que também interfere na sua implementação: a inserção de estudantes oriundos de classes sociais menos favorecidas no sistema escolar brasileiro e a inclusão dos alunos com Necessidades Educacionais Específicas - NEE. Esta ampliação do público da educação é oriunda da compreensão do papel da escola ante a diversidade humana, implicando na revisão das estratégias de ensino e, consequentemente, a avaliação da aprendizagem neste espaço educacional, de modo a promover o atendimento às diferenças.

Com a inserção de pessoas com NEE na escola (como pessoas com deficiência, com superdotação, com transtornos globais do desenvolvimento, entre outros), vemos a indispensabilidade de identificar os pressupostos e práticas que favoreçam a educação (e a avaliação) dos estudantes que apresentam particularidades nos modos de aprender. Essa 
diferença pode ser gerada a partir do uso de línguas diferentes daquelas compartilhadas pela maioria da turma ou necessitem de recursos promotores de acessibilidade, além da atenção às temporalidades específicas para a aquisição do conhecimento. Neste contexto, para conhecer a eficiência do processo educativo é relevante conhecer adaptações voltadas para o processo de identificação dos conhecimentos consolidados pelos discentes, bem como daqueles que precisam ser trabalhados de forma diferenciada, de modo a ser apropriado eficazmente pelos estudantes.

Entre os alunos público-alvo da Educação Especial (na perspectiva inclusiva), destacamos o aluno surdo. Este discente, por utilizar a Língua Brasileira de Sinais - Libras como primeira língua - L1 encontra dificuldades para aprender e expressar os conhecimentos no sistema educacional brasileiro que prioriza o aprendizado do português (um sistema de comunicação que, para o surdo, se configura na sua segunda língua - L2) limitando as suas possibilidades de compreensão e de produção do conhecimento.

Diante do exposto, surgiu o interesse em identificar as orientações legais e as práticas relatadas por autores que realizaram investigações sobre a temática a fim de compreender as adaptações necessárias para a realização de uma avaliação real e justa, voltada para identificar os avanços do educando e contribuir com a consolidação do conhecimento pelo estudante surdo durante determinada etapa do ensino. Para tanto, delimitamos como objetivo geral identificar (na legislação e na literatura) pressupostos, recursos e práticas de avaliação para surdos a fim de refletir sobre as condições que otimizem este processo.

Dessa maneira, definimos como percurso metodológico a pesquisa exploratória, pautada na análise documental e na revisão da literatura. Inicialmente, visitamos a legislação que trata da avaliação na perspectiva da educação inclusiva, identificando as referências sobre as abordagens, recursos, instrumentos e procedimentos no que concerne à avaliação do surdo. Na sequência, realizamos o levantamento de trabalhos completos publicados em anais de alguns eventos nacionais e internacionais, além de artigos, dissertações e teses nos quais a avaliação compusesse o tema central.

Para a análise bibliográfica inserimos, no dia 25 de outubro de 2018, na ferramenta de busca do repositório Scientific Electronic Library Online - Scielo, os descritores "avaliação do surdo" e obtivemos 1 ocorrência. Em seguida, utilizamos os mesmos descritores para a pesquisa parametrizada no site Google Acadêmico e obtivemos 24 ocorrências. Excluímos as pesquisas nas quais a avaliação não fosse o ponto central da investigação, ou seja, não compusesse o título do trabalho, bem como aquelas que tinham um dos autores desta investigação como pesquisador. Diante disso, refinamos 7 ocorrências, com publicações 
compreendidas no período entre 2013 e 2018, sendo 4 artigos publicados em revistas ${ }^{4}$ e 3 trabalhos completos publicados em anais de eventos (2 em nacionais ${ }^{5}$ e 1 em internacional ${ }^{6}$ ). Um deles foi excluído por apresentar conteúdo semelhante publicado em uma revista e em anais de evento. Nesta situação, optamos por utilizar o artigo em revista por observar que este passou por revisão e ter sido divulgado em data posterior ao trabalho publicado em anais.

Devido ao número restrito de publicações que versam sobre a temática, esta pesquisa é relevante no sentido de contribuir para compilar as discussões na área da avaliação para repensar meios que possam torná-la mais acessível às pessoas surdas e, dessa forma, apresentar pressupostos, estratégias e instrumentos que possibilitem que o processo avaliativo se torne mais eficaz e democrático para os estudantes com NEE.

Nesta investigação nos fundamentamos na perspectiva sócioantropológica da surdez (SKLIAR, 2001), na qual o surdo é conceituado a partir da sua diferença linguística, como um usuário da Libras e do Português escrito, conforme define a Lei da Libras $n^{\circ}$ 10.436/2002. Seguindo esta linha de compreensão da surdez, a filosofia educacional bilíngue para surdos é a abordagem educacional na qual embasamos esta perspectiva de avaliação. Para Pereira et al. (2013), o bilinguismo compreende o ensino da Língua de Sinais como L1 e da língua majoritária do país (preferencialmente na modalidade escrita) como L2 para o estudante surdo.

Diante disso, dividimos o trabalho em: pressupostos sobre a avaliação; avaliação do surdo: um percurso histórico; avaliação do surdo sob a perspectiva dos documentos legais; e experiências de avaliação da pessoa surda.

\section{Pressupostos sobre a avaliação}

De acordo com a Lei de Diretrizes e Bases da Educação Nacional - LDB nº 9.394/1996, no Art. 24, inciso V, a avaliação é um componente da prática educativa que deve ser realizada de maneira contínua e acumulativa. Para tanto, os aspectos qualitativos devem prevalecer ante aos quantitativos a fim de possibilitar a identificação, com maior clareza do rendimento do aluno. $\mathrm{O}$ parágrafo $8^{\circ}$ do Art. 35 desta lei explica que: "Os conteúdos, as metodologias e as formas de avaliação processual e formativa serão organizadas nas redes de ensino por meio de atividades teóricas e práticas, provas orais e escritas, seminários, projetos e atividades on-line” (BRASIL, 1996), ou seja, utilizando-se de diferentes instrumentos na sua aplicação.

\footnotetext{
${ }^{4}$ Estudos de Avaliação na Educação (2015); Linguagens Educação e Sociedade (2017); Educação e Fronteiras On-line (2017); Polyphonia (2018).

${ }^{5}$ Congresso Brasileiro Multidisciplinar de Educação Especial (2013); Congresso Nacional de Educação (2017).

${ }^{6}$ Congresso Internacional sobre Investigación em Didactica de las Ciencias (2017).
} 
Sobre a finalidade da avaliação, Gremaud et al. (2009) dividem-na em três grupos: diagnóstica, formativa e somativa. A avaliação diagnóstica busca compreender as habilidades e competências consolidadas, aquelas que estão em processo de aquisição, bem como as que precisam ser desenvolvidas nos educandos. A avaliação formativa, para esses autores buscam identificar os avanços individuais e os obstáculos que se apresentam no decorrer de determinada etapa ou nível de ensino. A avaliação somativa, por sua vez, é realizada no final do processo de aprendizagem, tem como objetivo a prática da verificação do aprendizado.

Libâneo (2007) afirma que, a fim de que o professor possa atingir os objetivos da educação, é necessário que esteja atento a três momentos: o planejamento da atividade, a direção do ensino e da aprendizagem e a avaliação. Sobre este último, o autor apresenta três atividades a serem observadas: análise do desempenho do professor; verificação do conhecimento alcançado pelo aluno; conhecimento de diferentes instrumentos de avaliação.

Sobre o desempenho do professor, o Libâneo (2007) indica que o docente deve verificar se o rendimento do aluno está compatível com os objetivos traçados pelo educador, de modo que possa repensar estratégias didáticas de acessibilizar o conteúdo aos discentes, de observar o momento em relação ao conhecimento de que os alunos já dispõem e servem como base para outros aprendizados.

Para o estudioso, a verificação do conhecimento compreende "o domínio dos meios e instrumentos de avaliação diagnóstica, isto é, colher dados relevantes sobre o rendimento dos alunos, verificar dificuldades, para tomar decisões sobre o andamento do trabalho docente, reformulando-o quando os resultados não forem satisfatórios” (LIBÂNEO, 2007, p. 73). Por fim, o investigador destaca a necessidade de uso de variados instrumentos para ressaltar o aspecto qualitativo da avaliação.

Silva e Kanashiro (2015) asseveram que, para os surdos, as avaliações na modalidade escrita da Língua Portuguesa geram dados incompletos relativos ao conhecimento do aluno sobre o assunto o que pode levar a interpretações equivocadas concernentes ao processo de internalização do conteúdo por esses estudantes. Isso ocorre porque, ao passo que o aluno ouvinte é avaliado na sua L1, o surdo realiza esta atividade na L2, sendo requerido, a este último, tanto a compreensão do conteúdo quanto de uma L2. De acordo com os autores, esta prática gera frustração nos surdos, pois evidencia as dificuldades de compreensão e produção na L2.

Diante do exposto, Hoffmann (2013) esclarece que a avaliação compreende um processo reflexivo e dinâmico indissociado da ação de educar. Contudo, para a superação da concepção de que avaliar é atribuir uma nota (sugerindo uma perspectiva de verificação) é necessário ao docente repensar o conceito e o processo de avaliação. Para isso, é fundamental 
entendê-la como parte instigadora do processo que compreende os movimentos de ação docente - reflexão sobre a prática - reorganização da ação educativa.

Na mesma obra, Hoffmann (2013) trata da avaliação na perspectiva da inclusão que é balizada por dois fatores: a revisão do conceito de avaliação como prática de classificação e a garantia de profissionais para atender aos alunos considerando as suas especificidades. Ao abordar a avaliação para o aluno surdo a pesquisadora nos convida à seguinte reflexão:

O que significa aprender em relação ao aluno surdo, o que significa aprender em relação ao aluno ouvinte? São essas as questões que irão mobilizar os professores a avalia-los e não se o aluno surdo 'aprendeu ou não como o ouvinte', da mesma forma que não se pretende comparar um aluno ouvinte a outro aluno ouvinte (HOFFMANN, 2011, p. 35)

Neste sentido, Bolsanello e Ross (2005) corroboram com a autora ao afirmar que a perda auditiva traz possibilidades diferenciadas de acesso ao conhecimento, sendo estas pautadas na visualidade. Diante disso, as experiências visuais devem permear todo o processo educativo desses estudantes, incluindo a etapa da avaliação da aprendizagem.

Conforme destacado, a concepção de avaliação está intrinsecamente relacionada à visão de educação e da ação docente sobre o processo de aprendizagem bem como sobre a função da atividade avaliativa, portanto, faz-se necessário conhecer as indicações sobre avaliação do surdo presentes nos documentos legais que norteiam esta prática no sistema educacional brasileiro.

\section{Avaliação do surdo sob a perspectiva dos documentos legais}

No Brasil, as primeiras experiências de educação bilíngue ocorreram no segundo império quando, a convite do imperador D. Pedro II, Hernest Huet fundou a primeira escola brasileira para atender alunos surdos. Inicialmente, a instituição utilizava a abordagem bilíngue, mas, após 1880, atendendo às orientações dos educadores de surdos na época, adotou o oralismo, uma abordagem educacional que perdurou até a década de 1970 (GOLDFELD, 2002). Para Pereira et al. (2013), o oralismo defende uma educação pautada no desenvolvimento da fala e não abre espaço para o uso da língua de sinais. Pouco mais de dez anos depois, estudos na área do bilinguismo apresentaram novas perspectivas de educação da pessoa surda que foram ratificadas em diferentes documentos educacionais.

Em 1994, na Espanha, o Brasil foi signatário da Declaração de Salamanca, um documento oriundo da Conferência Mundial de Educação Especial. Neste documento, há uma orientação, no ponto 18, para que o ensino dos surdos seja mediado pela Língua de Sinais. Já no ponto 29 do mesmo texto, há o direcionamento para a prática da avaliação 
formativa que se caracteriza como aquela que se diferencia do sistema de classificação e, portanto, visa à melhoria do processo educativo (SALAMANCA, 1994).

No mesmo ano, o Ministério da Educação e Cultura - MEC expediu o Aviso Circular $n^{\circ} 277$ destinado às universidades a fim de esclarecer sobre a avaliação da pessoa com deficiência para o ingresso no nível superior considerando os recursos necessários para atender as NEE desse público. Neste ofício é ressaltada que a política de avaliação proposta para a pessoa com NEE foi motivada pelas pesquisas na área (realizadas pelas universidades) bem como pela reivindicação desse público e dos seus familiares demonstrando, assim, a relevância da pesquisa e da mobilização popular para a melhoria das condições de educação. Diante disso, vemos a importância da discussão e proposição de ações voltadas para as práticas de acesso e permanência das pessoas com NEE no sistema educacional (BRASIL, 1994).

Ainda neste documento são elencadas as ações a serem realizadas para acessibilizar as informações ao surdo, sendo estas divididas em três momentos: a divulgação do edital, a aplicação das provas e a etapa da correção. De acordo com o aviso expedido pelo MEC, no corpo do edital, é necessária a descrição dos recursos dos quais o estudante pode dispor durante a realização da prova, como também os critérios a serem considerados durante a correção do instrumento de avaliação. A aplicação das provas deve ser realizada em sala especial e a avaliação deve considerar as formas possíveis de obtenção de respostas pelo educando. Sobre a correção, precisa considerar as especificidades de construção do conhecimento pelo estudante e, para isso, devem ter "critérios compatíveis com as características especiais desses alunos" (BRASIL, 1994, p. 1)

Dentre os encaminhamentos previstos pelo MEC para o atendimento da pessoa surda destacamos: constituição de banca de avaliação diferenciada, composta por (ao menos) um especialista na área da deficiência do candidato; presença de um Tradutor-Intérprete da Língua de Sinais - TILS; além de:

[...] flexibilidade nos critérios de correção da redação e das provas
discursivas dos candidatos portadores de deficiência auditiva, dando
relevância ao aspecto semântico da mensagem sobre o aspecto formal e/ou
adoção de outros mecanismos de avaliação da sua linguagem em
substituição a prova de redação. (BRASIL, 1994, p. 1).

Esta especificidade da correção das avaliações dos surdos foi reafirmada cinco anos depois, com a expedição da Portaria do MEC nº 1679/1999 (BRASIL, 1999).

Em 2001, a Resolução $\mathrm{n}^{\circ} \mathrm{O} 2$ do Conselho Nacional de Educação - CNE e do Conselho de Educação Básica - CEB divulgou as diretrizes e as orientações necessárias para promover a modalidade da Educação Especial no nível da Educação Básica. Neste documento 
é atribuído às escolas da Educação Básica a responsabilidade da utilização de processos adequados de avaliação de modo a promover o desenvolvimento desses alunos, sem maiores especificações sobre as formas de implementação.

Um ano após a publicação dessa resolução, a Libras foi reconhecida como um sistema linguístico oficial do Brasil, com a Lei ${ }^{\circ}$ 10.436/2002. Nesta legislação, a Libras é definida como meio de comunicação da comunidade surda e a sua utilização não deve substituir a modalidade escrita da Língua Portuguesa estimulando, assim, o repensar a educação na perspectiva bilíngue (BRASIL, 2002). Três anos depois, o Decreto $n^{\circ}$ 5.626/2005 que regulamentou a Libras, explica as modificações necessárias para tornar o processo de avaliação do surdo mais equânime. No art. 14 do referido texto, define que as instituições federais que ofertam serviços educacionais devem:

Garantir, obrigatoriamente, às pessoas surdas acesso à comunicação, à informação e à educação nos processos seletivos, nas atividades e nos conteúdos curriculares desenvolvidos em todos os níveis, etapas e modalidades da educação, desde a educação infantil até a educação superior (BRASIL, 2005).

Este decreto prevê ainda a avaliação diferenciada pelo surdo, considerando a utilização da Língua Portuguesa como L2 e, para tanto, enfatiza a correção nos aspectos semânticos do texto em detrimento dos sintáticos. Este aspecto da avaliação do surdo é reafirmado na Lei $\mathrm{n}^{\circ}$ 13.146/2015, que institui a Lei Brasileira de Inclusão da Pessoa com Deficiência - LBI, também conhecida como Estatuto da Pessoa com Deficiência - EPD (BRASIL, 2015).

Retomando o Decreto 5.626/2005 é garantida ainda a avaliação em Libras desde que haja o registro do processo em vídeos salvos em mídias digitais. Essa medida possibilita a revisão da avaliação caso haja discordância das considerações ou da nota atribuída ao estudante ou candidato.

A seguir, veremos algumas reflexões sobre aspectos a serem considerados na avaliação da pessoa surda, sendo estes oriundos de vivências e/ou análises realizadas por educadores de diferentes regiões do Brasil.

\section{EXPERIÊNCIAS DE AVALIAÇÃO DA PESSOA SURDA}

Conforme enfatizamos no decorrer da investigação, concordamos com Luckesi (2011) ao destacar que o processo de avaliação não pode ser dissociado de práticas de ensino que valorizem diferentes formas de expressão do estudante. Diante disso, as concepções de ensino e de avaliação, na atualidade, devem estar alinhadas à legislação vigente, pois elas refletem as permanências ou as mudanças das práticas do sistema educacional. 
No entanto, o educador precisa estar atento para repensar a sua prática e buscar conhecer a legislação educacional que orienta a avaliação, como também as experiências divulgadas na literatura. Assim, essas práticas, oriundas de investigações que geraram experiências exitosas podem contribuir para repensar o processo avaliativo de modo que o docente possa incorporar estratégias e/ou recursos que visam qualificar o processo avaliativo.

Partindo destas reflexões, um fato comum encontrado nos trabalhos que compõem esta reflexão é a compreensão de que a avaliação é uma etapa do processo de ensino e deve ser pensada de modo a atender as especificidades dos alunos no que se refere às estratégias, aos recursos (humanos e materiais) bem como às práticas e instrumentos avaliativos. Diante disso, dos 7 trabalhos analisados, oriundos de investigações bibliográficas ou que refletem investigações de campo (mostrando dados de diferentes regiões do país), organizamos no quadro 1, uma síntese dos trabalhos selecionados para compor esta reflexão.

QUADRO 1 - Pesquisas discutidas nesta investigação

\begin{tabular}{|l|l|l|l|}
\hline Ano & Autores & Instrumento de coleta de dados & Publicação \\
\hline 2013 & $\begin{array}{l}\text { Mahl; } \\
\text { Ribas }\end{array}$ & $\begin{array}{l}\text { Questionários aplicados a professores da } \\
\text { rede municipal de uma cidade do Paraná. }\end{array}$ & $\begin{array}{l}\text { Anais/evento } \\
\text { nacional }\end{array}$ \\
\hline 2015 & $\begin{array}{l}\text { Silva; } \\
\text { Kanashiro }\end{array}$ & $\begin{array}{l}\text { Entrevistas com 4 surdos (EJA) submetidos a } \\
\text { um instrumento de avaliação visual no IFSP - } \\
\text { Cubatão }\end{array}$ & Revista \\
\hline 2017 & Gonçalves et al. & $\begin{array}{l}\text { Entrevista despadronizada a 1 coordenadora e } \\
\text { O2 professoras de uma escola municipal de } \\
\text { Santa Izabel - PA }\end{array}$ & $\begin{array}{l}\text { Anais/evento } \\
\text { nacional }\end{array}$ \\
\hline 2017 & $\begin{array}{l}\text { Freitas-Reis et } \\
\text { al. }\end{array}$ & $\begin{array}{l}\text { Apresentação e análise de atividades } \\
\text { avaliativas para ensino de química }\end{array}$ & $\begin{array}{l}\text { Anais/evento } \\
\text { internacional }\end{array}$ \\
\hline 2017 & $\begin{array}{l}\text { Rodrigues; } \\
\text { Gonçalves }\end{array}$ & $\begin{array}{l}\text { Entrevista e observação de 11 educadores, } \\
\text { sendo: 1 coordenador; 4 professores } \\
\text { intérpretes; 6 professores regentes. }\end{array}$ & Revista \\
\hline 2017 & $\begin{array}{l}\text { Oliveira; Silva e } \\
\text { Gomes }\end{array}$ & $\begin{array}{l}\text { Análise bibliográfica sobre a temática } \\
\text { Onálise bibliográfica sobre a temática }\end{array}$ & Revista \\
\hline
\end{tabular}
Fonte: Próprios autores (2018).

Compilamos as informações dessas pesquisas em 4 eixos temáticos: Formação e atuação docente; Parceria com o TILS e o professor do Atendimento Educacional Especializado - AEE; Instrumentos e critérios avaliativos; contribuições para repensar a avaliação na perspectiva inclusiva.

Ressaltamos que o objetivo deste trabalho é refletir sobre pressupostos e processos de avaliação, por isso, não nos deteremos na análise da relação do surdo com a escrita da língua 
portuguesa, mas de recursos, estratégias e instrumentos que favoreçam a percepção do conhecimento consolidado pelo estudante surdo.

\section{Formação e atuação docente}

Mahl e Ribas (2013) buscando identificar a percepção dos professores sobre a avaliação de surdos na escola regular aplicaram questionários com 9 professores que atuavam no ensino fundamental de uma rede municipal de ensino do Paraná. Sobre as estratégias utilizadas para ensinar os alunos surdos, aproximadamente $30 \%$ dos professores afirmam utilizar recursos visuais e posicionar-se no campo de visão dos estudantes durante a explicação do conteúdo e pouco mais de $15 \%$ usam gestos, expressões faciais ou Libras durante as interações em classe. Diante disso, os colaboradores afirmam a necessidade de formação docente para o trabalho com o aluno surdo e para o uso da Libras, sendo apontadas como soluções mais urgentes para melhorar a prática pedagógica.

Dados relevantes sobre a análise da aplicação da avaliação ressaltada por esses docentes é que cerca de $20 \%$ deles afirmam apresentar, com clareza os conteúdos a serem avaliados e ressaltam que valorizam os acertos, respeitam o ritmo de aprendizagem do aluno, entretanto, este número diminui para pouco mais de $15 \%$ para aqueles que apresentam atividades de recuperação paralela para que o aluno tenha uma segunda oportunidade de demonstrar o conhecimento consolidado no processo. Diante desses dados, podemos inferir que no contex to explicitado pelos investigadores, a avaliação somativa é priorizada por esses educadores.

Gonçalves et al. (2017) afirmam que, na realidade estudada, tanto a coordenadora quanto as professoras encontram dificuldades em identificar os instrumentos adequados para a avaliação de uma aluna surda, portanto, não há adaptação no material. Os educadores flexibilizam o tempo de prova e citam, como justificativa a quantidade e a extensão dos textos que compõem o instrumento de avaliação, bem como a necessidade de uso do aplicativo de tradução automática da Libras para a Língua Portuguesa (e vice-versa) denominado Hand Talk (disponível para download gratuito para smartphones) e que auxilia a aluna na tradução de palavras e sentenças presentes na prova.

Nas pesquisas de Mahl e Ribas (2013), Silva e Kanashiro (2015), Gonçalves et al. (2017) a formação docente é apresentada como uma ação urgente a ser implementada para que os educadores conheçam os pressupostos para a avaliação do aluno surdo. Nesse sentido, comparando os relatos e a legislação vigente, vemos que o desconhecimento sobre as leis e as orientações sobre a avaliação do surdo geram práticas que não correspondem àquelas propostas da educação inclusiva, reforçando a necessidade de repensar a formação docente. 


\section{Parceria com o TILS e o professor do AEE}

Dois dos colaboradores da pesquisa de Mahl e Ribas (2013) trazem considerações interessantes tecidas pelos professores sobre o papel do TILS na avaliação: o primeiro disse que este profissional era responsável por realizar a escrita da sinalização do surdo, ou seja, uma tradução da resposta. O segundo afirmou realizar as mesmas provas para surdos e ouvintes, sendo o TILS o único recurso de acessibilidade nesta ocasião.

Rodrigues e Gonçalves (2017) identificaram que em uma escola de ensino fundamental do Distrito Federal - DF a responsabilidade da avaliação do surdo fica a cargo do TILS (denominado pelos autores como professor intérprete) e do profissional que atua no AEE. O AEE é previsto desde a Constituição Federal de 1988 e é definido no Art., $2^{\circ}$, Incisos I e II, do Decreto $n^{\circ} 7.611 / 2011$ como atividades, inserção de recursos de acessibilidade ou pedagógicos que visam:

I - complementar à formação dos estudantes com deficiência, transtornos globais do desenvolvimento, como apoio permanente e limitado no tempo e na frequência dos estudantes às salas de recursos multifuncionais; ou II suplementar à formação de estudantes com altas habilidades ou superdotação (BRASIL, 2011)

Oliveira et al. (2018), ao estudarem o processo de mediação do TILS na avaliação do surdo no ensino superior, identificaram que a presença desse profissional é essencial tanto nos momentos de apresentação do conteúdo quanto de avaliação. Entretanto, somente a presença do TILS é insuficiente. Para as autoras, é necessário o envolvimento de toda a equipe "para que haja aceitação e respeito às diferenças e o desenvolvimento de uma prática pedagógica assertiva” (OLIVEIRA et al., 2018, p. 137). As investigadoras ressaltam que muitos docentes não compreendem os limites do trabalho do intérprete duvidando dos seus princípios éticos e do rendimento apresentado pelo educando no processo avaliativo.

As pesquisadoras defendem que TILS e professores devem ser parceiros no processo de avaliação, pois, devido à particularidade linguística do surdo, o TILS poderá sugerir atividades ou identificar dificuldades dos alunos e informá-las ao professor, de modo que juntos possam trabalhar em prol do desenvolvimento do aluno. Essa constatação também é observada no trabalho de Oliveira, Silva e Gomes (2017). A partir desses trabalhos, vemos a importância da delimitação da função de cada profissional e do trabalho colaborativo entre eles.

\section{Instrumentos e critérios avaliativos}


Mahl e Ribas (2013) identificaram que, no momento da avaliação, os recursos visuais não são citados diretamente. Como estratégias utilizadas pelos docentes são apresentadas, por aproximadamente $44,5 \%$ dos colaboradores, a observação da participação e interesse dos estudantes nas atividades. Os demais utilizam somente a Língua Portuguesa na modalidade escrita (o que corresponde a 11, 1\%) e os demais mesclam avaliações escritas em Língua Portuguesa (com correção diferenciada) e em Libras (em geral, sem o registro em vídeo).

Nesta investigação, as avaliações mesclam a coleta de informações sobre o aprendizado de três modos: produção textual escrita (considerando aspectos semânticos ante aos gramaticais); produção textual em Libras; e análise de aspectos qualitativos (oriundos da observação nas participações e no conhecimento expresso pelos alunos durante as aulas). Diante das informações dos professores, notamos que os instrumentos de avaliação precisam ser diferenciados para atender aos alunos surdos e esta percepção destaca a necessidade de proporcionar adaptações desde o momento destinado às atividades de ensino do conteúdo até à etapa da avaliação.

Já Silva e Kanashiro (2015) observaram que 4 surdos estudantes da Educação de Jovens e Adultos - EJA, no Instituto Federal de São Paulo - IFSP recebiam a colaboração dos colegas para o registro das atividades em Língua Portuguesa propostas, contudo, no momento da avaliação, contavam com a interpretação do TILS para a compreensão do enunciado, mas tinham que registrar os conteúdos em Língua Portuguesa. Notamos, assim, uma distância entre a prática de ensino (colaborativa) e a avaliação (individual) e que acontecia na L2 do surdo, limitando as possibilidades de expressão desses indivíduos.

Diante disso, os investigadores propuseram a produção das avaliações na perspectiva das vídeo-provas em Libras e, para tanto, utilizaram a plataforma HyperText Markup Language (HTML) para produzir questões que contassem com diferentes línguas e linguagens para a sua composição e, com isso, permitir a compreensão da pessoa surda. Cada questão era composta por uma imagem relacionada ao assunto central a ser avaliado, uma janela com a sinalização das instruções, das questões e das alternativas em Libras (utilizando os sinais de conhecimento dos surdos da classe ou convencionalizados - entre os surdos e o TILS - durante a explicação). Essas informações foram acompanhadas do registro em Língua Portuguesa na modalidade escrita refletindo um recurso construído na perspectiva bilíngue. Na figura 1, vemos o layout da plataforma utilizada na pesquisa para a avaliação: 
FIGURA 1 - Vídeo prova em Libras

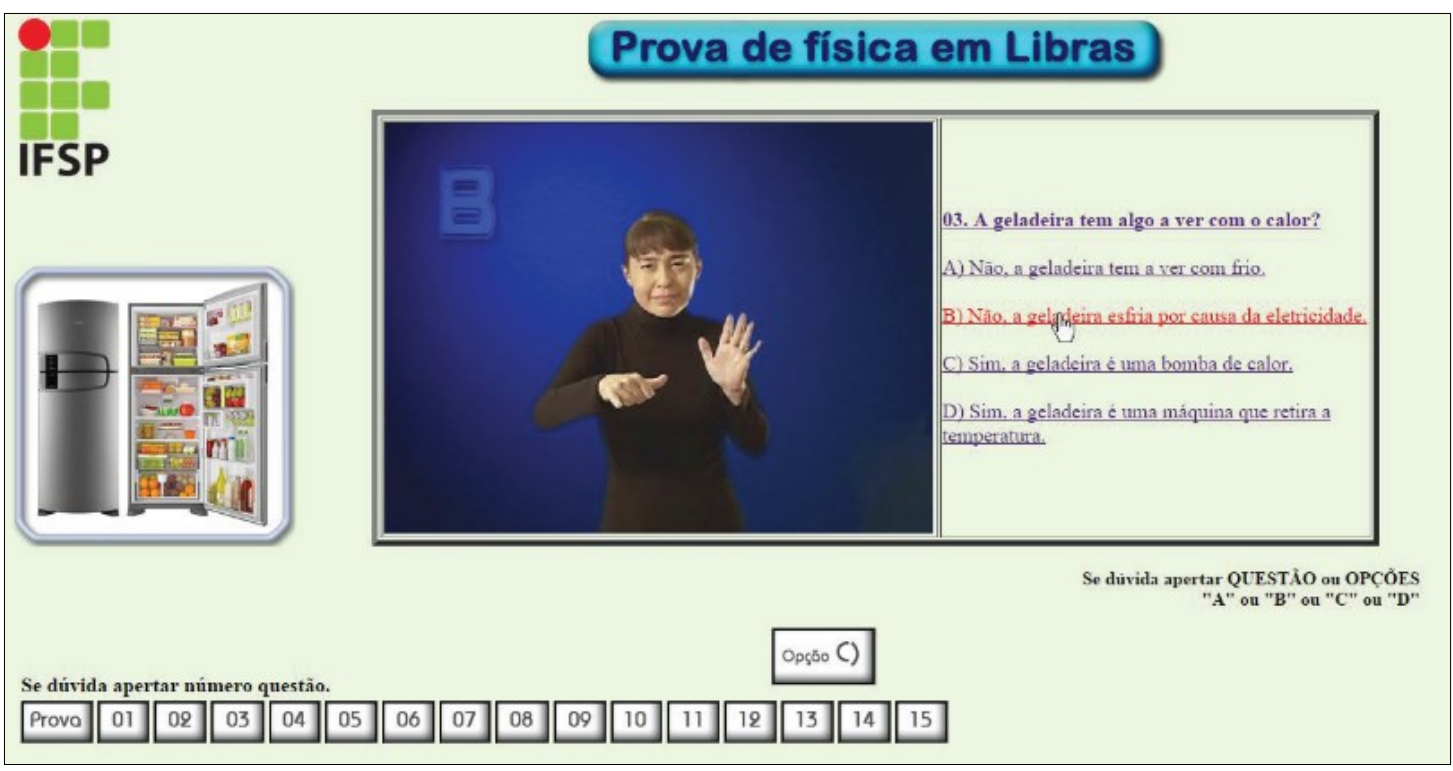

Fonte: Silva e Kanashiro (2015)

Esta atividade foi proposta para as avaliações bimestrais e, no decorrer das quatro aplicações, tanto os instrumentos quanto as formas de apresentação precisaram ser ajustadas em função das dificuldades percebidas pelos aplicadores. Nas duas primeiras aplicações, as vídeo-provas foram aplicadas utilizando-se o datashow e um notebook, por isso, os surdos não tinham autonomia em rever determinada questão no momento no qual considerassem mais apropriado. Visto isso, as duas últimas aplicações ocorreram no laboratório de informática possibilitando ao aluno surdo rever questões quantas vezes fossem necessárias (desde que respeitado o tempo total de prova), resolvê-las no seu próprio tempo ou selecionar aquelas que deveriam ser respondidas primeiro, permitindo, desse modo, autonomia na resolução da prova. Nas palavras das autoras: “A avaliação visual operada pessoalmente aproxima ainda mais as condições do aluno surdo da dos alunos ouvintes, colocando sob controle de cada um o ritmo e o andamento da prova em relação ao tempo disponível” (SILVA; KANASHIRO, 2015, p. 710).

Neste estudo, os investigadores destacam que essa abordagem de avaliação contribuiu não só para valorizar o processo de aprendizagem de conteúdo, como também o processo de aprendizado em Libras, tornando os estudantes mais participativos e confiantes quanto ao seu potencial para a aprendizagem. 
A avaliação proposta pelos autores é próxima àquela disponibilizada pelo Instituto Nacional Anísio Teixeira - INEP, durante o Exame Nacional do Ensino Médio - ENEM. Essa avaliação foi divulgada no site de compartilhamento de vídeos YouTube e, na figura 2, vemos o layout da página da prova

FIGURA 2 - Layout da vídeo-prova em Libras

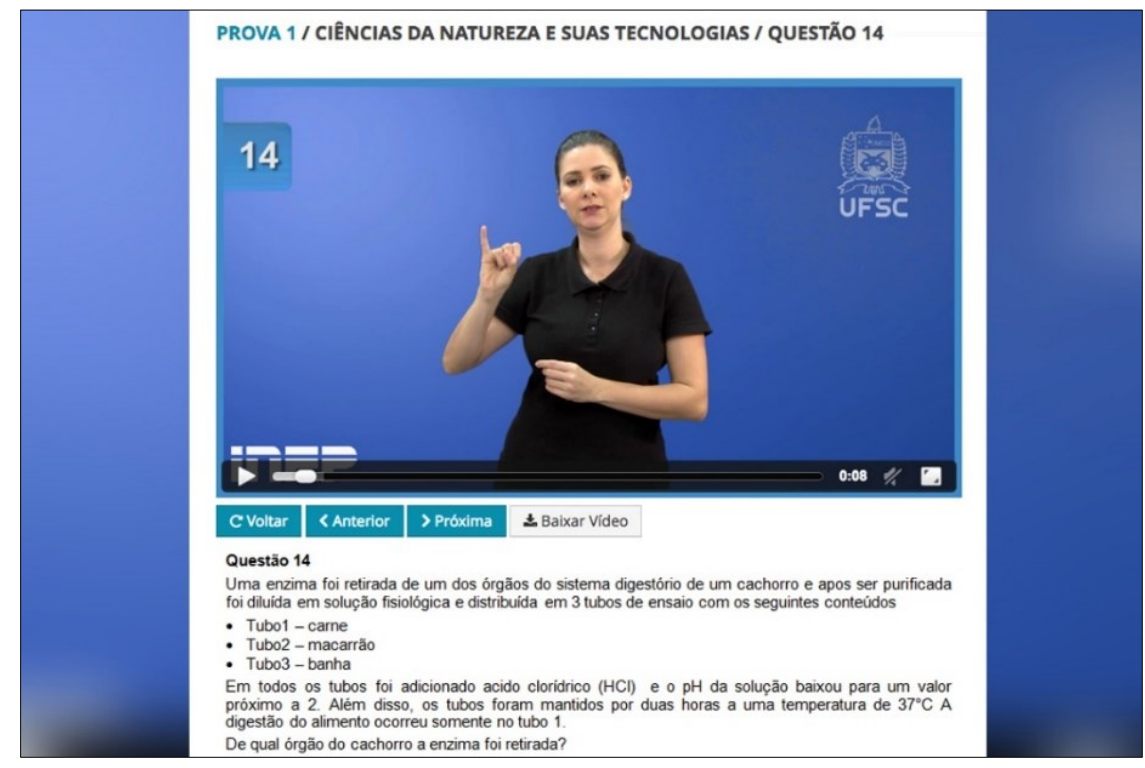

Fonte: Revista Veja (2017)

Freitas-Reis et al. (2017) apresentam recursos oriundos de recortes de duas dissertações de mestrado que tratavam de métodos e/ou processos de ensino e aprendizagem do surdo. Esses estudos retratam intervenções realizadas em 2015 e 2016, com alunos surdos do Ensino Médio, na cidade de Juiz de Fora - MG.

A primeira trata do uso de desenhos para a representação do balanceamento das reações químicas, proposta por meio de desenhos, envolvendo alunos surdos e ouvintes. A experiência associou experimentos sobre reações químicas e o registro por meio de desenhos que foram discutidos após a elaboração. A atividade favoreceu a percepção de erros conceituais dos alunos e a realização da intervenção adequada de modo a dirimir as dúvidas sobre os conteúdos.

Já a segunda, discutiu o uso de fotografias e tratou da identificação de processos químicos e físicos. De acordo com os autores, após relacionar as imagens, os estudantes foram convidados a criar uma história (em Libras), contextualizando a imagem ao processo de reação. Nessa atividade, além do caráter interdisciplinar (produção de narrativas conteúdo trabalhado nas aulas de língua - e o conteúdo reações - ensinado em química), foi possível aproximar a teoria e o cotidiano, ao passo que os estudantes relacionaram as imagens a cinco situações vivenciadas por eles que envolveram esses fenômenos. 
E ressaltam a urgência das instituições de ensino repensarem as práticas de avaliação considerando o aluno surdo, ou seja, inserindo a Libras, respeitando a identidade e cultura surda que são pautadas na visualidade. Sobre esta temática, Oliveira, Silva e Gomes (2017) chegaram à mesma constatação.

\section{Contribuições para repensar na perspectiva da avaliação inclusiva}

Diante do exposto, vemos que a compreensão do conceito de inclusão é fundamental para repensar as práticas avaliativas pautadas nesta perspectiva. Para tanto, o docente precisa compreender as especificidades dos alunos para buscar tanto as parcerias quanto os instrumentos adequados para acessibilizar a avaliação e, desse modo, compreender os avanços e as dificuldades apresentadas pelo educando no processo de ensino e de aprendizagem.

As propostas apresentadas acima corroboram com a percepção apresentada por Gonçalves et al. (2017) ao afirmarem que a avaliação deve ter como finalidade identificar os percursos de aprendizagem dos alunos de modo a propor novos caminhos que os faça avançar. Diante disso, o docente não pode se prender a um único modo de avaliar.

Sobre o envolvimento familiar na construção do processo de construção do conhecimento e as suas relações com o sistema avaliativo, Silva e Kanashiro (2015) e Gonçalves et al. (2017) ressaltam a importância do acompanhamento para o êxito nas atividades escolares. Eles asseveram que devido aos materiais didáticos serem disponibilizados em Língua Portuguesa, os surdos sentem dificuldades de encontrar interlocutores (no ambiente familiar) que esclareçam suas dúvidas quanto às informações disponibilizadas neste sistema linguístico, sendo necessário o trabalho articulado entre os diferentes componentes da comunidade escolar.

A necessidade de envolvimento de todos os grupos que compõem a escola é destacada, ainda, no trabalho de Oliveira, Silva e Gomes (2017). Os autores acrescentam que, para favorecer uma avaliação mais justa é imprescindível conhecer o estudante, sua forma de aprender e os recursos disponíveis para promover esse aprendizado.

Vemos assim que a implementação da acessibilidade, em diferentes espaços educacionais, passa pelo trabalho coletivo e integrado, envolvendo educadores, técnicos e funcionários que, mesmo desconhecendo aspectos específicos da aprendizagem do aluno, podem compor os grupos de trabalho, para juntos colaborarem com a inclusão dos educandos.

\section{Considerações finais}


A avaliação da aprendizagem tem como finalidade proporcionar a compreensão dos conhecimentos consolidados e repensar as práticas educativas favorecendo o aprendizado dos discentes. A compreensão da avaliação como um processo reflexivo e que visa gerar a otimização dos processos de aprendizagem deve ser considerado pelos educadores. A partir desta constatação, a concepção dos docentes sobre a avaliação e sobre as características dos surdos, bem como sobre os recursos humanos e materiais que podem somar na efetivação da acessibilidade ao conhecimento são indispensáveis para propor uma atividade avaliativa mais inclusiva e reflexiva, sendo este um aspecto que consideramos relevante como objeto para futuras investigações nessa área.

Diante do exposto, vemos que a legislação prevê adaptações para o processo avaliativo da pessoa surda de modo a valorizar a Libras e, assim, funcionar como instrumento de verificação do aprendizado do conteúdo ministrado pelo professor. Neste processo, a valorização da Libras e de estratégias visuais no processo de avaliação do surdo (em oposição às práticas oralistas) são essenciais para identificar os conhecimentos consolidados pelos estudantes.

Assim, esses instrumentos precisam ser elaborados em uma perspectiva bilíngue, além de pautarem-se em práticas que possam aproximar surdos e ouvintes na elaboração das atividades propostas. Além disso, estas atividades devem favorecer a compreensão (pelo docente) do nível de desenvolvimento do surdo e das formas que facilitam o aprendizado dos estudantes.

Contudo, para desenvolver uma prática efetiva, faz-se necessária a reorganização do sistema educacional, de modo a aproximar professores e intérpretes, investir na formação continuada dos educadores (docentes e técnicos), esclarecer e envolver a comunidade escolar nas atividades propostas e buscar instrumentos e estratégias diferenciadas de avaliação de modo a identificar os caminhos para uma gestão mais democrática do processo de construção do conhecimento.

\section{Referências}

BRASIL. Aviso Circular $n^{\circ}$ 277, de 08 de maio de 1994. Disponível em: < http://portal.mec.gov.br/seesp/arquivos/pdf/aviso277.pdf>. Acesso em: 24 out. 2018.

BRASIL. Lei n. 9.394, de 20 de dezembro de 1996. Dispõe sobre as Diretrizes e Bases da Educação Nacional (LDBEN). Diário Oficial da União, Brasília, DF, 23 dez. 1996. https://doi.org/10.5380/jpe.v10i20.49964

BRASIL. Portaria $n^{\circ} 1679$, de 2 de dezembro de 1999. Dispõe sobre requisitos de acessibilidade de pessoas portadoras de deficiências, para instruir os processos de autorização e de reconhecimento de cursos, e de credenciamento de instituições. Disponível em: <http://portal.mec.gov.br/sesu/arquivos/pdf/c1_1679.pdf>. Acesso em: 24 out. 2018. https://doi.org/10.17648/galoa-cbee-6-28373 
BRASIL. Resolução CNE/CEB $n^{\circ}$ O2, de 11 de setembro de 2001. Institui Diretrizes Nacionais para a Educação Especial na Educação Básica. Disponível em: < http://portal.mec.gov.br/cne/arquivos/pdf/CEBo201.pdf>. Acesso em: 24 out. 2018. https://doi.org/10.22294/eduper/ppge/ufv.v8i1.708

BRASIL. Lei $n^{\circ}$ 10.436, de 24 de abril de 2002. Dispõe sobre a Língua Brasileira de Sinais Libras e dá outras providências. Diário Oficial da União, Brasília, DF, 25 abr. 2002. Disponível em: <http://www.planalto.gov.br/ccivil_03/LEIS/2002/L10436.htm>. Acesso em: 24 out. 2018. https://doi.org/10.1590/0034-716719730005000016

BRASIL. Decreto $n^{\circ}$ 5.626, de 22 de dezembro de 2005. Regulamenta a Lei no 10.436, de 24 de abril de 2002, que dispõe sobre a Língua Brasileira de Sinais - Libras, e o art. 18 da Lei no 10.098, de 19 de dezembro de 2000. Diário Oficial da União, Brasília, DF, 23 dez. 2005. Disponível em: <https://presrepublica.jusbrasil.com.br/legislacao/96150/decreto-562605>. Acesso em: 24 out. 2018. https://doi.org/10.12660/rda.v1.1945.8533

BRASIL. Decreto $n^{\circ} 7.611,17$ de novembro de 2011. Dispõe sobre a educação especial, o atendimento educacional especializado e dá outras providências. Diário Oficial da União, Brasília, DF, 18 nov. 2011. Disponível em: <http://www.planalto.gov.br/ccivil_03/_Ato2011-2014/2011/Decreto/D7611. htm\#art1 1>. Acesso em: 24 out. 2018. https://doi.org/10.17648/galoa-cbee-6-28370

BRASIL. Lei $n^{\circ}$ 13.146, de 06 de julho de 2015. Institui a Lei Brasileira de Inclusão da Pessoa com Deficiência (Estatuto da Pessoa com Deficiência). Diário Oficial da União, Brasília, DF, 7 jul. 2015. Disponível em: < http://www.planalto.gov.br/CCIVIL_03/_Ato20152018/2015/ Lei/L13146.htm>. Acesso em: 24 out. 2018. https://doi.org/10.26668/indexlawjournals/2526-0022/2017.v3i1.1811

BOLSANELLO, M. A.; ROSS, P. A. Educação Especial e avaliação da aprendizagem na escola regular. Curitiba: Ed. da UFPR, 2005. Disponível em: < http://www.cinfop.ufpr.br/pdf/colecao_1/educ_esp_7.pdf>. Acesso em: 23 nov. 2018.

FREITAS-REIS, I et al. Métodos de avaliação para o aluno surdo no contexto de química. In: CONGRESSO INTERNACIONAL SOBRE INVESTIGACIÓN EM DIDACTICA DE LAS CIENCIAS, 10., 2017, Sevilla, Anais...Sevilla: Enseñanza de Las Ciencias. $\mathrm{N}^{\circ}$ extraordinário, 2017. p. 4009 - 4014. https://doi.org/10.5565/rev/ec/v31n1.1143

GOLDFELD, M. A criança surda: linguagem e cognição numa perspectiva sociointeracionista. $3^{\text {a }}$ ed. São Paulo: Plexus Editora, 2002.

GONÇALVES, A. G. da C. et al. A avaliação da aprendizagem e o aluno surdo. In: CONGRESSO NACIONAL DE EDUCAÇÃO, 12., 2017, Curitiba. Anais...Curitiba: Editora Universitária Champagnat, 2017. Disponível em: < http://educere.bruc.com.br/arquivo/pdf2017/24395_12387.pdf>. Acesso em: 23 nov. 2018.

GREMAUD, A. P. et al. Guia de estudo: avaliação continuada. Juiz de Fora: Fadepe, 2009.

HOFFMANN, J. Avaliar para promover: as setas do caminho. Porto Alegre: Mediação, 2011. 
HOFFMANN, J. Avaliação: Mito \& Desafio. Uma perspectiva construtivista. Porto Alegre: Mediação, 2013.

INEP. Video-prova em Libras do Enem 2017 está disponível no YouTube do INEP. Disponível em: $\quad<$ http://www.brasil.gov.br/noticias/educacao-e-ciencia/2017/11/videoprova-emlibras-do-enem-2017-esta-disponivel-no-youtube-do-inep>. Acesso em: 23 nov. 2018. https://doi.org/10.24824/978854441890.1

LIBÂNEO, J. C. Didática. São Paulo: Ed. Cortez, 2007.

LUCKESI, C. C. Avaliação da aprendizagem escolar: estudos e proposições. $22^{a}$ ed. São Paulo: Cortez, 2011.

MAHL, E.; RIBAS, V. A. Avaliação escolar para alunos surdos: entendimentos dos professores sobre este processo. In: CONGRESSO BRASILEIRO MULTIDISCIPLINAR DE EDUCAÇÃO ESPECIAL. 7., 2013, Londrina. Anais...Londrina: UEL, 2013. p. 584 - 595. https://doi.org/10.17648/galoa-cbee-6-27974

OLIVEIRA, S. M. et al. O intérprete educacional de Libras: a mediação no processo de avaliação do aluno surdo. Polyphonia: Revista de Educación Inclusiva, n. 2, ano 1, p. 131 - 149, 2018.

OLIVEIRA, C. V.; SILVA, F. B.; GOMES, V. L. A avaliação do surdo na escola regular. Educação e Fronteiras On-line. Dourados/MG, v. 7, n. 19, p. 71-78, jan/abr 2017.

PEREIRA, M. C. M. et al. Libras: conhecimento além dos sinais. São Paulo: Pearson Prentice Hall, 2013.

REVISTA VEJA. Novo recurso é mais uma opção aos candidatos, que já contavam com auxílios de tradutor-intérprete de libras ou de leitura labial na hora da prova. 2017. Disponível em: https://veja.abril.com.br/educacao/candidatos-surdos-vao-poder-prestar-o-enem-por-videoprova/. Acesso em: 23 nov. 2018. https://doi.org/10.28998/2317-9945.2018v1n60p87-101

RODRIGUES, F. B. de M.; GONÇALVES, L. P. A avaliação do aluno surdo em classe inclusiva na rede pública de ensino do Distrito Federal. Revista Linguagens Educação e $\begin{array}{lllllllll}\text { Sociedade. Teresina, ano } 22, \quad \text { n. } 37, & \text { p. } 172 & - & 189, & 2017 .\end{array}$ https://doi.org/10.26694/les.v1i37.7582

SALAMANCA. Declaração de Salamanca. 1994. Disponível em: <http://portal.mec.gov.br/seesp/arquivos/pdf/salamanca.pdf>. Acesso em: 24 out. 2018.

SILVA, E. L.; KANASHIRO, E. Avaliação Visual da Aprendizagem: uma alternativa para os alunos surdos. Estudos de Avaliação na Educação. São Paulo, v. 26, n. 63, p. 688 - 714, 2015. https://doi.org/10.18222/eae.voix.3111

SKLIAR, C. et al. Educação \& Exclusão: Abordagens Sócio-Antropológicas em Educação Especial. $3^{\mathrm{a}}$ ed. Porto Alegre: Editora Mediação, 2001. 